\title{
Energy Scenarios for Ambitious and Effective Nigerian's Nationally Determined Contributions
}

\author{
E.O. Diemuodeke ${ }^{1, *}$ C. Okereke ${ }^{2}$ \\ ${ }^{1}$ Energy and Thermofluid Research Group, Department of Mechanical Engineering, Faculty of Engineering, \\ University of Port Harcourt, PMB 5323, Choba. \\ ${ }^{2}$ Centre for Climate Change and Development, Alex Ekwueme Federal University (AE-FUNAI), Ndufu- \\ Alike \\ * E-mail of the corresponding author: ogheneruona.diemuodeke@uniport.edu.ng
}

This paper is an outcome of a project undertaken by the Center for Climate Change and Development, Alex Ekwueme Federal University Ndufu-Alike (AE-FUNAI), in partnership with World Resources Institute (WRI) Washington DC with funding from IKEA Foundation

\begin{abstract}
Nigeria's Nationally Determined Contribution (NDC) shows commitment to supporting the Paris Agreement towards reducing the global warming and negative impacts of climate change. However, some gaps need to be bridged in order to make Nigeria's NDC more ambitious and effective. Therefore, this paper presents energy scenarios that could support the revision of existing Nigeria's NDC to ambitiously limit GHG emissions while promoting increased access to green energy. The paper systematically establishes gaps in the existing NDC, namely circumvention of subsisting energy-related policies, lumped energy efficiency pathways, overconcentration on solar PV, neglect of the residential sector, neglect of advanced emissions control technology and neglect of on-grid renewable energy utilisation. The paper also presents pertinent recommendations to bridge the established gaps, which are critical for the NDC revision. It is pertinent that the NDC revision should consider all the aspects of energy supply and demand sides in a transparent and equitable process. It envisaged that the judicious and equitable consideration of the recommendations in this work would make Nigeria's NDC ambitious and effective.
\end{abstract}

Keywords: nationally determined contributions, energy sector, energy policies, demand-side energy efficiency, residential sector

DOI: $10.7176 / \mathrm{JETP} / 10-7-04$

Publication date: December $30^{\text {th }} 2020$

\section{Introduction}

All over the world, energy is a central consideration in climate change policy. In Nigeria, the intersection between energy and climate is broad, multiple and complex. First, given the high rate of energy poverty and a fast-growing population, there is huge pressure on Nigeria to vastly increase energy generation and distribution from its vast fossil fuel reserves. According to World Bank figures, only $40 \%$ of Nigeria's 200 million population is connected to the national grid and well over $70 \%$ of the rural population depend on traditional biomass for cooking (see Figure 1) (Nigerian Bureau of Statistics, 2019) 

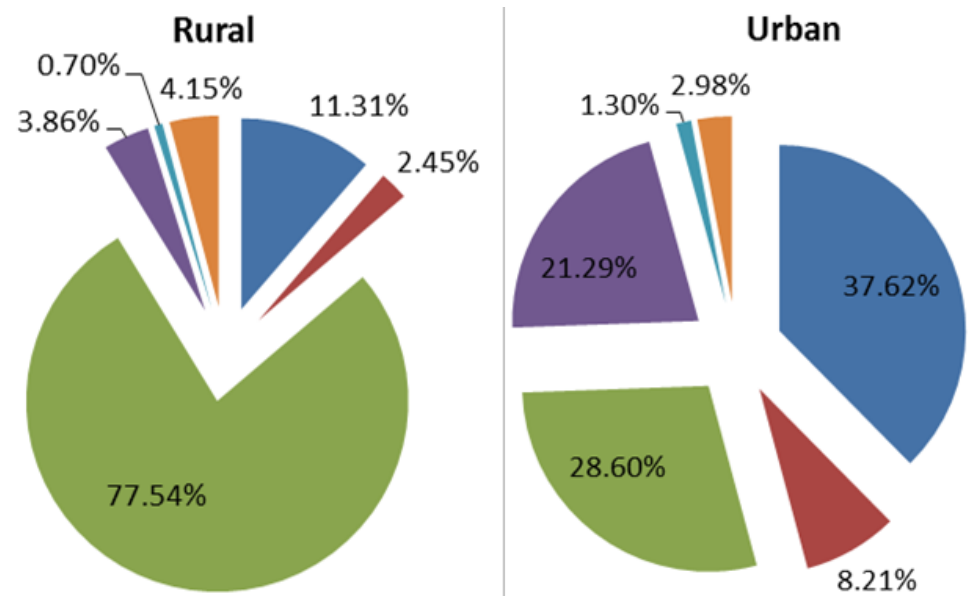

- Kerosene

- Charcoal/coal

airewood

- LPG/Cooking gas

Electricity

- Other

Figure 1. Percentage distribution of energy sources for cooking (Nigerian Bureau of Statistics, 2019)

The second major point of intersection is that the energy sector, which plays a critical role as the key enabler of other sectors such as agriculture, health and water, is prone to climate change variabilities. At the grid level, the power generation capacity is dependent on both ambient conditions (temperature and humidity) and water level of which could be severely altered by climate change (Klimenko et al., 2018). For example, a rise in temperature (with corresponding humidity) will affect the performance of gas turbine power plants. Similarly, the performance of hydropower plants can be impacted by the quantity and pattern of rainfall. As noted by Nigerian experts in the power sector, the grid power network in Nigeria is grossly limited leaving a large proportion of dwellers in both urban and rural communities to depend on off-grid energy sources (mostly firewood and agrowastes) for their cooking and heating needs. In rural communities, energy access is also highly vulnerable to climate change given their dependence on biomass (firewood and agro-wastes). For the southern zones, energy access is vulnerable to flooding, windstorm and erosion (Haider, 2019). In the northern zones, access to energy is more impacted by extreme heat, windstorm, drought and desert encroachment (Haider, 2019). Thirdly, the activities in the oil and gas sector (especially gas flaring and oil spillage) have a significant impact on greenhouse gas emissions, climate vulnerability, ecological integrity, and the livelihood of a large population. For these reasons, a clever and strategic treatment of energy is vital in Nigeria's Nationally Determined Contributions and for any prospects of achieving a low carbon development.

\section{Energy-Related Commitments in the Current NDC}

The existing NDC acknowledges the important position of energy is occupying in the development of Nigeria's economy. In this perspective, the NDC identified the energy sector as critical to achieving the Paris Agreement through the pillars of decentralized renewable energy, improving power generation stations and the electricity grid, enforced energy efficiency and shift from liquid fuels to natural gas usages. The NDC considers a range of energy-related measures as part of the plan to achieve a reduction of emissions, which are projected to grow by $114 \%$ by 2030 reaching about $900 \mathrm{MtCO}_{2}$ under a business as usual (BAU) scenario. The reduction would be achieved by actions in five sectors of the economy listed below: energy, oil and gas, agriculture and land use, industry, and transport.

Notably, for the energy sector, the NDC reduction actions consider linear improvement in energy efficiency by $2 \%$ per year to reach $30 \%$ by 2030 ; providing $13 \mathrm{GW}$ off-grid solar PV electricity to rural communities that are currently off- or under-grid, improved electricity grid transmission and distribution efficiency to minimise transmission losses, and ending the flaring of gas by converting it to useful energy through appropriate gas-touseful energy conversion technologies - natural gas generator, LPG cookstove, and natural gas engine bus for examples. The emissions reduction actions in all the sectors considered in the NDC would lead to a $20 \%$ reduction compared to BAU, which is the basis of the unconditional NDC. A commitment to higher emission reduction is made conditional to international support. The conditional pledge includes increasing energy efficiency and drastically reducing the use of fossil fuel-based generators. This would lead to a $45 \%$ reduction of emissions in 2030 compared to BAU, or 18\% increase from 2015 emissions level.

The NDC demonstrates its determination to contribute to the success of the Paris climate through the unconditional and conditional pledges. The NDC indicates a commitment to contribute to the sustainable growth 
of Nigeria's economy. However, the Nigerian economy is heavily dependent on income from oil and gas production $-90 \%$ of the exports and $15 \%$ of GDP. Therefore, energy has an important impact to influence the climate policy in the country; where the demand for oil and gas is reduced. In this regard, the energy sector should be systematically dissected for possible opportunities that will positively impact the environment in the revision of Nigeria's Nationally Determined Contributions (NDC).

\section{Energy Policies in Nigeria that are Relevant to the NDC}

There is an evidence that in setting the energy-related goals in the current NDC, the government attempted to create a link with the relevant existing policy in the country. The Nigerian government has long prioritised energy access for all judging from the plethora of energy policies and regulatory frameworks in the energy sector. For example, the 2005 Renewable Energy Master Plan (REMP) that pertains the support for the development of renewable energy sources for both small- and large-scale applications pledged to generate at least $10 \%$ of the total energy consumption from renewable energy by 2025. The 2006 National Policy and Guidelines on Renewable Electricity aimed at generating 5\% of the total electricity from renewable sources by 2016 . The National Energy Master Plan (NEMP) targeted to facilitate decarbonisation of the country's development pathway through renewable energy technologies application; and the 2015 National Renewable Energy and Energy Efficiency Policy (NREEEP), which was published a few months before the conclusion of the NDC, plans to vigorously pursue the deployment of renewables in its electricity generation, and embark on efficient energy management, which is targeted at $40 \%$ energy efficiency by 2030 at $2.5 \%$ yearly improvement.

Particularly, REMP and NREEEP have a significant role in decarbonising the energy sector of Nigeria. The REMP targeted to increase the renewable energy share in the total energy consumption of the country to at least $10 \%$ by 2025 . The pathway to achieving the target is by increasing renewable electricity from $13 \%$ of the country's total electricity generation in 2015 to $23 \%$ in 2025 , which will progress to $36 \%$ by 2030 . It can, therefore, be argued that this target was more diverse than the NDC narrow target of solar PV electricity generation.

In what follows, the electrification rate will be improved from $42 \%$ to $75 \%$ in 2025 . The NREEEP was designed to respond to both the modern energy supply crisis in Nigeria and Nigeria's commitment to the Paris Agreement by increasing the utilisation of renewable energy and application of energy-efficient systems and appliances. The NREEEP identified renewable energy resources, at an economic potential assessment, that could produce $68 \mathrm{GW}$ of both on-grid and off-grid electricity (about 17 times the current electricity generation capacity in the country). However, the NDC has entrapped on only off-grid solar PV electricity generation at a generation capacity of $13 \mathrm{GW}$, which is over ambitious compared to the relevant policy targets. It is possible to achieve a significant proportion of the targeted potential $68 \mathrm{GW}$ of electricity generation to bridge the huge gap between supply and demand to reduce the proliferation of inefficient and polluting liquid fuel generators. It is obvious that the NDC did not consider the potential of renewable energy to support diverse energy mix for both on-grid and off-grid energy access.

\section{Energy-Based Analysis of the Existing NDC}

\subsection{The Ambition Gap}

The central challenge for the NDC with regards to energy is that it has to walk a tight balance between the urgent need for more energy generation to improve access across the country and the need to keep energy-related emissions from increasing based on BAU scenario. The existing NDC as indicated commits to a significant reduction of emissions by improving some of the energy-related SDG indicators, namely access to electricity, access to clean energy, etc. However, the approach and data used in developing the NDC are largely opaque, which may have contributed to the poor performance of the country's energy-related SDG indicators, namely access to electricity (59.3\% of the population), access to clean fuel for cooking ( $4.9 \%$ of the population) and reduction of $\mathrm{CO}_{2}$ emission from fuel combustion/electricity output $\left(\mathrm{MtCO}_{2} / \mathrm{TWh}\right)$ (Sachs, et al 2019). It has been shown that improved energy-related SDG indicators induce the development of any nations. The Nigeria economy was on the rapid increase, with the standard of living tending to the higher side, before its downturn as a result of declining international oil prices coupled with the recent COVID-19 pandemic (Ozili 2020). Ultimately, energy is required to revive the economy and to sustain the growing population, which is expected to double over the next 25 years. However, there is a conflicting burden of widening energy access and reducing emissions to avoid average global temperature above $2{ }^{\circ} \mathrm{C}$ of the pre-industrial era. As indicated, the way the 
NDC attempts to address this tension is by committing to reduce emission through $2 \%$ yearly energy efficiency (to reach $30 \%$ by 2030), deployment of $13 \mathrm{GW}$ off-grid solar PV, efficient gas generators and the improved electricity grid to reduce transmission losses. However, the existing NDC ambition seems to be crafted on poor data, circumvention of subsisting energy policies and ill-defined methodology.

\subsection{The Neglect of the Demand-Side Energy Efficiency}

The second gap is that the existing NDC focuses mainly on the supply-side of the energy chain - generation, transmission and distribution - and neglects demand-side energy management, or at best these two have been lumped together in a way that does not help in policy design, implementation and monitoring. In the supply-side, efficiency is expected to be driven by technology innovation response, namely upgrade gas-fired power plants (e.g combined heating and power plants), create more efficient transmission and distribution and capturing waste heat. No doubt, these are all important and established approach for minimising energy consumption, emission and enhancing productivity (Bataille and Melton 2017; IEA 2017). However, they are often capital intensive and technology innovation-driven, which often makes it more difficult for developing countries with limited financial and technological capacity to implement. Whereas in the demand side (demand-side management), efficiency is driven more by technology and behavioural responses a big part of which could be more readily implemented by the government. It has been noted that the adoption of smart energy management systems (e.g. smart switches) in home and offices could substantially reduce energy consumption vis-à-vis emission (Zipperer et al. 2013; Khan 2019).

The NREEEP identified the demand-side energy efficiency in the household and industry sectors as a fulcrum to achieve the $40 \%$ energy efficiency, at a $2.5 \%$ yearly improvement, target. The policy identifies the use of efficient household appliances, in particular for lighting, cooking, refrigeration, and productive uses to significantly improve the energy efficiency landscape. The policy shows that good energy management (simple housekeeping measures) in the industry can save at least $25 \%$ energy. In this regard, the policy committed the Federal Government to promote and support the adoption of energy-saving appliances and devices in all sectors of the country. Certainly, there is a significant difference between the NREEEP $40 \%$ energy efficiency target and the NDC $30 \%$ energy efficiency target at the same 2030 time horizon. The implication is that energy scenarios should be designed in recognition of the appropriate weighting factors for the energy efficiency sides - the supply-side and the demand-side - and the adequate consideration of the subsisting energy policy energy efficiency target.

\subsection{Over Concentration on Solar PV}

Another important gap in the current NDC is the concentration on off-grid solar PV as the only means to achieve the $13 \mathrm{GW}$ target of electricity generation from renewable sources. It is true that solar PV off-grid electrification has gained significant policy drives and research attention in recent decades, especially in this country. However, narrowing on only solar PV to meet the $13 \mathrm{GW}$ of off-grid electrification seems to be too ambitious. The NREEEP targeted to meet $1.343 \mathrm{GW}$ and $6.831 \mathrm{GW}$ of electricity generation from solar energy by 2020 and 2030, respectively, which is far below the 13 GW NDC target of only off-grid solar PV electrification. Certainly, the target of $13 \mathrm{GW}$ renewable energy penetration will not be met, as suggested by the NREEEP and Bamisile et al. (2020a), due to the local entrapment of the only solar PV electrification. The NDC, to a large extent, circumvents subsisting energy policies; for example, the REMP, NREEEP etc.. The REMP and NREEEP targeted to simultaneously consider all potentially viable renewable energy sources for on- and off-grid applications for household and productive uses, which is not reflected in the existing NDC.

The NDC mainly touted the electrical form of energy, without the due considerations of other forms of energy, thermal energy for example - it could be because electricity is the most demanded form of energy. In doing so the NDC fails to seriously consider the need to promote a robust and diverse energy mix which several experts have held as being important for climate resilience and energy security.

Other commercially proven renewable energy conversion technologies in the market support climate change mitigation, namely solar thermal, wind turbine, small hydropower and bioenergy, see Table 1 for NREEP targets, which support decentralised off-grid power generation. There are substantial potentials for the utilisation of solar thermal, wind turbine, small hydropower and bioenergy technology in the country judging from a plethora of literature in the open domain (Nyeche and Diemuodeke 2020; Bamisile et al. 2020b). For example, UNIDO commissioned an off-grid 0.4 MW small hydropower plant in the Northern part of the country in 2014, and many of such projects are expected to follow soon. There is a high potential of bioenergy in the country and it has seen growing interest in the recent time (Oyedepo et al. 2019). The application of bioenergy in electricity generation is a matured technology globally, for example, agro-waste-to-energy power plant. The implication is that other 
viable technologies could be used to drive the off-grid energy access in Nigeria that did not feature in the NDC.

Table 1. Nigeria's Energy Potentials (Source: Federal Ministry of Power 2015)

\begin{tabular}{cllll}
\hline \multirow{2}{*}{ S/No } & \multirow{2}{*}{ Energy Source } & \multicolumn{3}{c}{ Timeline } \\
\cline { 3 - 5 } & Hydropower (large and small) -MW & 2015 & 2020 & 2030 \\
\hline 1 & Biomass electricity -MW & 5 & 6,156 & 12,801 \\
3 & Biofuel -ML/day & 7.3 & 57 & 292 \\
4 & Solar -MW & 117 & 13.1 & 35.9 \\
5 & Wind -MW & 55 & 631 & 6,831 \\
\hline
\end{tabular}

\subsection{Neglect of the Residential Sector}

Another significant gap in the NDC is that it fails to seriously consider the need for energy supply to the residential sector. Given that the residential sector currently consumes a significant proportion of the country's primary energy as shown in Figure 2, it is not possible to imagine a meaningful or effective socioeconomic development and climate change action that does not have residential energy transition as a key thrust (Selvakkumaran and Ahlgren 2019).

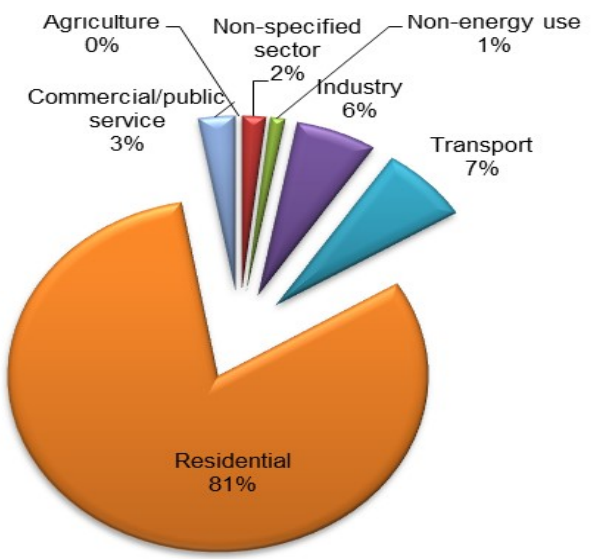

Figure. 2. Sectoral primary energy consumption in 2015 (source: Edomah 2019)

In many of the residential sector, energy demand for cooking and heating is dominated by non-clean energy technology, only $10 \%$ access to clean cooking (IEA 2019). The rural communities, which constitute about $50 \%$ of the population, depend on inefficient fossils, firewood, charcoal and agro-wastes cookstoves to meet their cooking and heating energy needs. The implication is that off-grid clean energy solutions towards cookstoves would play a vital role in the decarbonisation of the residential sector. It is, therefore, a big gap that the NDC did not seriously consider how to close the energy access gap for the rural population. It is desirous for the future NDC should fashion energy scenario for the adoption of clean cooking technology in line with the National Gas Policy and the adoption of other clean cooking technologies - e.g. improved biomass cookstove (Moses, Pakravan, and MacCarty 2019).

\subsection{Reducing Emission from Fossil Fuel-fired Energy Systems}

Another gap in the current NDC is that it does not sufficiently consider options for greening emissions from the main sources of production which is fossil fuel-fired power plants. Currently, about $75 \%$ of total on-grid generation in Nigeria comes from gas-fired power stations. Looking in the future some analyses have suggested that energy mix in the country will continue to be dominated by fossil fuel (see Figure 3). Given the vast amount of gas reserves in the country and the current sunk cost in the gas-fired power generation, which currently accounts for the power generation in the country, it is difficult to see how the energy portfolio can shift significantly away from natural gas in the near future. Therefore, a key aspect of the low carbon development policy should be to figure out ways to reduce the carbon emission implications of gas-fired power generation 
through the application of downstream technology, carbon capture and sequestration (CCS) for example (Ugwuishiwu et al., 2019). The CCS is a proven global technology that is used to make fossil fuel-fired conventional power plants environmentally friendly.

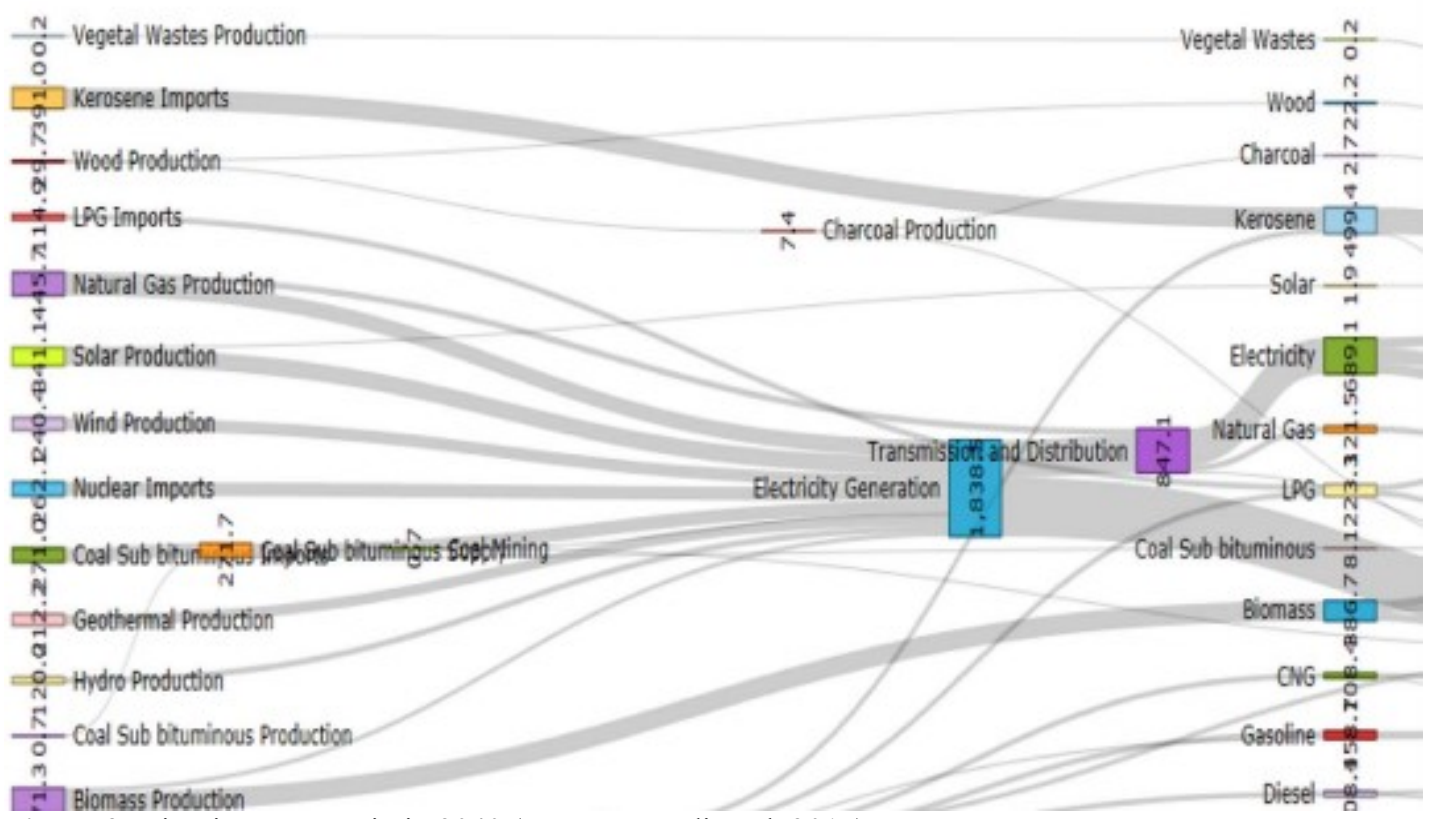

Figure 3. Nigeria Energy mix in 2040 (source: Emodi et al. 2017)

\subsection{Reducing Emission from Fossil Fuel-fired Energy Systems}

Policy-wise, Nigeria could be on the right track to compete favourably in the on-grid and mini-grid renewable energy revolution. However, institutional capacity and implementation challenges may impose turbulence on renewable energy innovation progress in Nigeria. Unfortunately, the current NDC does not mention on-grid let alone delve into the policy and institutional framework that is critical to catalyzing the scale and direction of innovation in the mini-grid area.

The Rural Electrification Agency of Nigeria (REAN) has identified renewable energy powered mini-grids as a cost-effective option for the rural electrification, which has created an exciting opportunity to rapidly adopt renewable electrification. The country large population and large economy make it attractive to investors in the energy access sector; the mini-grid market has revenue potential of US\$8 billion annually according to a publication of Nigerian Economic Summit Group (Yakubu et al, 2018). The mini-grid energy access market of the country is robust and rapidly growing with emerging best practices in energy generation and utilisation (Yakubu et al, 2018). The mini-grid sector of the country is rapidly shifting away from grant and seed funding towards private debt and equity capital to support the market potential of over 9 million households according to the International Energy Association market potential criterion (Scott and Miller, 2016). The stakeholders across the renewable energy utilisation value chain in the country can enable and accelerate this growth through a few key actions, e.g proper policy implementation and evaluation. These key actions are expected to present an exciting investment opportunity in the mini-grid that is destined to significantly increase energy access across Nigeria (Yakubu et al, 2018).

The off-grid electrification, no doubt, has the potential to support the rapidly growing economy and emission reduction (Nyeche and Diemuodeke, 2019). However, heavy reliance on the off-grid supply-side energy solutions by the NDC seems to counter common logic that increases in energy demand will be substantial in ongrid due to increase in economic activities in urban and peri-urban that are on-grid. The improved on-grid electricity that is captured in the NDC could be driven simultaneously by smart grid facilities and increase in ongrid renewable energy sources. For example, the Katsina wind farm has the capacity to generate $10 \mathrm{MW}$ on-grid electricity and many of these projects are expected to come on board in no distance time. The implication is that energy scenario that explores both on-grid and off-grid renewable energy technology is desirous especially as the cost of renewable energy technologies are coming down (see Figure 4). 


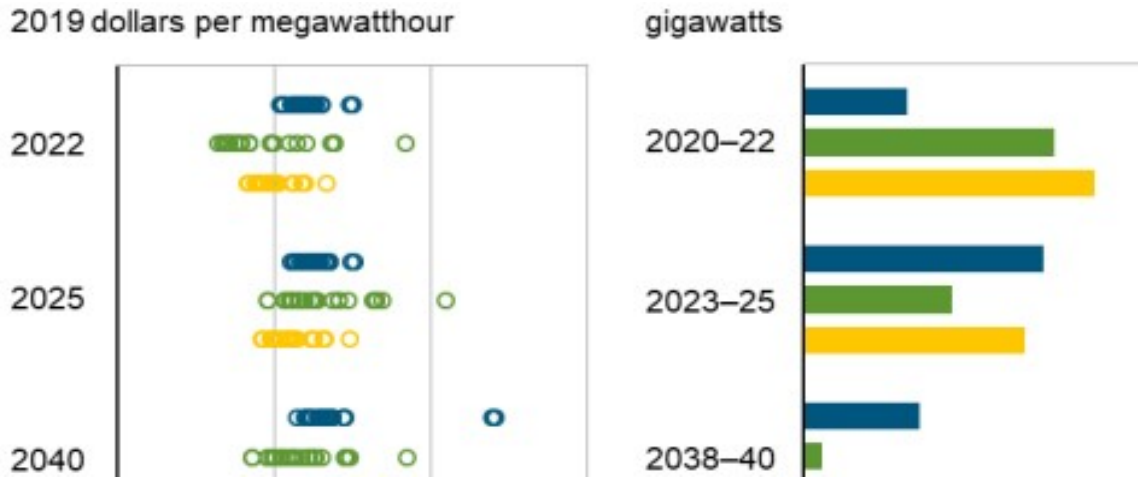

Figure 4. Levelised cost of energy technologies entering service in 2022, 2025 and 2040 (source: EIA 2020)

\section{Conclusion}

The current NDC makes important commitments in the energy sector, which could help limit GHG emissions while promoting increased access to green energy. However, there are many gaps such as circumvention of subsisting energy-related policies, lumped energy efficiency pathways, overconcentration on solar PV, neglect of the residential sector, neglect of advanced emissions control technology and neglect of on-grid renewable energy utilisation. It is, therefore, critical and pertinent that the NDC revision should consider all the aspects of energy supply and demand sides in a transparent and equitable process. In what follow, the NDC revision should judiciously and equitably consider;

- expanding the energy efficiency debate from both the supply-side and demand-side with clear accounting and monitoring pathways for supply-side energy efficiency and demand-side energy efficiency,

- a diverse energy mix from both on-grid and off-grid commercially proven renewable energy conversion technologies and applications,

- a critical review of bioenergy potentials in view of energy-environment-food nexus,

- the potential of clean and efficient energy utilisation in the residential sector by closing the energy access gap especially for the rural dwellers through policy and institutional framework that catalyse the scale and direction of innovation in the mini-grid energy access sector,

- a broad-based discussion on the potentials of modern cooking services especially for the off-grid communities,

- the application of advanced technologies for greening downstream of fossil fuel-fired energy systems, namely commercially proven carbon capture and sequestration and waste-to-energy technologies,

- holistically anchoring the NDC on all relevant subsisting energy-related policies through a transparent and replicable methodology by coupling information from the research community and public policy and

- designing a holistic implementation mechanism (finance, strategy, capacity building, and institutional development) that is specific to the energy sector, with friendly implementation process - adequate monitoring and evaluation plan.

To achieve the above, the new NDC should give attention to all the economic sectors of the country by exploring plausible emission avoidance opportunities, with the energy taking the appropriate priority as the key enabler of the other sectors. The NDC revision would be enhanced by considering the above in the major energy-dependent sectors, namely residential, commercial, public service, industrial, and agricultural, for plausible means of reducing energy-induced emissions.

\section{References}

Bamisile, O, Huang, Q, Xu, X, Hu, W, Liu, W, Liu, Z and Chen, Z (2020b). "An Approach for Sustainable Energy Planning towards $100 \%$ Electrification of Nigeria by 2030.” Energy 197: 117172. https://doi.org/10.1016/j.energy.2020.117172

Bamisile, O., Huang, Q, Ayambire, P, Anane, P.O.K, Abbasoglu, S and. Hu, W (2020a) "Analysis of Solar PV and Wind Power Penetration into Nigeria Electricity System", 2020 IEEE/IAS 56th Industrial and 
Commercial Power Systems Technical Conference (I\&CPS), Las Vegas, NV, USA, 2020, pp. 1-5, doi:10.1109/ICPS48389.2020.9176822.

Bataille, C. and Melton, N. (2017) "Energy efficiency and economic growth: A retrospective CGE analysis for Canada from 2002 to 2012", Energy Economics, 64: 118-130. https://doi.org/10.1016/j.eneco.2017.03.008

Edomah, N. (2019). "Governing Sustainable Industrial Energy Use: Energy Transitions in Nigeria's Manufacturing Sector." Journal of Cleaner Production 210: 620-29. https://doi.org/10.1016/j.jclepro.2018.11.052

EIA. (2020). "Levelized Cost and Levelized Avoided Cost of New Generation Resources in the Annual Energy Outlook 2020."

Emodi, N.V, Emodi, C. C, Murthy, G. P and Emodi.A.S.A (2017). "Energy Policy for Low Carbon Development in Nigeria: A LEAP Model Application.” Renewable and Sustainable Energy Reviews 68: $247-61$. https://doi.org/10.1016/i.rser.2016.09.118

Federal Ministry of Power. (2015). "National Renewable Energy and Energy Efficiency Policy."

Haider, H. (2019) "Climate change in Nigeria: impacts and responses", K4D. https://assets.publishing.service.gov.uk/media/5dcd7alaed915d0719bf4542/675 Climate Change in N igeria.pdf. Accessed: 10 Sept. 2020.

IEA. (2017). "Market Report Series: Energy Efficiency 2017.”

IEA. (2019). "Nigeria Energy Outlook 2019.” https://www.iea.org/articles/nigeria-energy-outlook

Khan, I. (2019). "Energy-Saving Behaviour as a Demand-Side Management Strategy in the Developing World: The Case of Bangladesh.” International Journal of Energy and Environmental Engineering 10 (4): 493 510. https://doi.org/10.1007/s40095-019-0302-3

Klimenko, V.V., Fedotova, E.V and Tereshin, G. (2018) "Vulnerability of the Russian power industry to the climate change", Energy 142: 1010-1022. https://doi.org/10.1016/j.energy.2017.10.069

Moses, N.D., Mohammad H.P, and Nordica A.M. (2019). "Development of a Practical Evaluation for Cookstove Usability.” Energy for Sustainable Development 48: 154-63. https://doi.org/10.1016/j.esd.2018.12.003

Nigerian Bureau of Statistics. (2019). LSMS Integrated Surveys on Agriculture Nigeria General Household SurveyPanel, Wave 4.

Nyeche, E. N., and Diemuodeke, E.O. (2020). "Modelling and Optimisation of a Hybrid PV-Wind TurbinePumped Hydro Storage Energy System for Mini-Grid Application in Coastline Communities.” Journal of Cleaner Production 250: 119578. https://doi.org/10.1016/j.jclepro.2019.119578

Oyedepo, S.O., Dunmade, I.S., Adekeye, T., Attabo, A.A., Olawole, O.C., Babalola, P.O., Oyebanji, J.A., Udo, M.O., Kilanko, O., and Leramo, R.O. (2019) "Bioenergy technology development in Nigeria-pathway to sustainable energy development", Int. J. Environment and Sustainable Development 18(2): 175-205.

Ozili, P. K (2020) "COVID-19 Pandemic and Economic Crisis: The Nigerian Experience and Structural Causes”. http://dx.doi.org/10.2139/ssrn.3567419

Sachs, J., Schmidt-Traub, G., Kroll, C., Lafortune, G., Fuller, G. (2019) “Sustainable Development Report 2019”, New York: Bertelsmann Stiftung and Sustainable Development Solutions Network (SDSN).

Scott, A. and Miller, C. (2016), "Accelerating access to electricity in Africa with off-grid solar The impact of solar household solutions", Overseas Development Institute.

Selvakkumaran, S. and Ahlgren, E.O. (2019) "Determining the factors of household energy transitions: A multidomain study", Technology in Society 57: 54-75. https://doi.org/10.1016/j.techsoc.2018.12.003

Ugwuishiwu, B.O, Joel, N.N, and Chukwuemeka J.O. (2019) "Cost Analysis of Carbon Capture and Storage for Current Gas-fired Power Plants in Nigeria.” Greenhouse Gases: Science and Technology 9 (2): 370-86. https://doi.org/10.1002/ghg.1855

Yakubu, A., Ayandele, E., Sherwood, J., Olu, O.A., Graber, S. (2018) "Minigrid Investment Report: Scaling the Nigerian Market", The Nigerian Economic Summit Group. https://rmi.org/wpcontent/uploads/2018/08/RMI Nigeria_Minigrid Investment_Report 2018.pdf. Accessed: 15 Sept. 2020 . 
Zipperer, A, Aloise-Young, P.A, Suryanarayanan, S., Zimmerle, D., Roche, R., Earle, L., Christensen, D. and Bauleo, P. (2013). "Electric Energy Management in the Smart Home: Perspectives on Enabling Technologies and Consumer Behavior: Preprint.” NREL. Vol. Ja-5500-57. 